\title{
Removal of Sulfur Dioxide by Carbon Impregnated with Triethylenediamine, Using Indigenously Developed Pilot Scale Setup
}

\section{Sidra Shaoor Kiani ( $\nabla$ sidrachm5@gmail.com )}

Hazara University

\section{Atif Ullah}

PIEAS: Pakistan Institute of Engineering and Applied Sciences

\section{Amjad Farooq}

PIEAS: Pakistan Institute of Engineering and Applied Sciences

\section{Masroor Ahmad}

PIEAS: Pakistan Institute of Engineering and Applied Sciences

\section{Naseem Irfan}

PIEAS: Pakistan Institute of Engineering and Applied Sciences

Mohsan Nawaz

Hazara University

\section{Research Article}

Keywords: Activated carbon, impregnation, adsorption capacity, challenge gas, breakthrough time, adsorption isotherms

Posted Date: June 17th, 2021

DOl: https://doi.org/10.21203/rs.3.rs-581847/v1

License: (9) This work is licensed under a Creative Commons Attribution 4.0 International License.

Read Full License

Version of Record: A version of this preprint was published at Environmental Science and Pollution Research on January 8th, 2022. See the published version at https://doi.org/10.1007/s11356-021-176536. 
3 Sidra Shaoor Kiani ${ }^{1,2^{*}}$, Atif Ullah ${ }^{1}$, Amjad Farooq ${ }^{1}$, Masroor Ahmad ${ }^{1}$, Naseem Irfan ${ }^{1}$, Mohsan 4 Nawaz $^{2}$

$5{ }^{1}$ Hazardous Air Pollutants Laboratory, Pakistan Institute of Engineering \& Applied Sciences 6 (PIEAS), Islamabad, Pakistan

$7 \quad{ }^{2}$ Department of Chemistry, Hazara University, Mansehra, Pakistan

\section{Using Indigenously Developed Pilot Scale Setup}

\section{ABSTRACT}

9 In order to provide protection against extremely toxic gases Activated Carbon (AC) adsorption has

long been regarded to be a useful technology in terms of gas removal. AC without chemical impregnation has been considerably less effective than impregnated ACs. AC in present use was modified with an organic amine i.e. triethylenediamine (TEDA) to enhance the physical and chemical properties of $\mathrm{AC}$ in order to remove specific poisonous gases. Purpose of this study was to assess the TEDA impregnated $\mathrm{AC}$ in terms of adsorption capability for simulant gas like $\mathrm{SO}_{2}$. Analysis was done in a properly designed setup. By using the scheme reported here, significant adsorption of toxic gas was obtained. Maximum removal capability observed by AC-4 for $\mathrm{SO}_{2}$ gas was $3.74 \mathrm{~g} / \mathrm{g}-\mathrm{C}$ and its breakthrough time was 264 minutes. Breakthrough time and adsorption capacity of AC-4 was found to be 25 times and 10 times greater as compared to raw AC. Different characterization techniques were also used to study impregnated AC. It was found that chemical adsorption was the crucial means by which TEDA impregnated AC removed the simulant gas. Langmuir model was best to represent equilibrium and adsorption kinetics follow second order model. The process was endothermic, favorable and spontaneous.

Keywords: Activated carbon, impregnation, adsorption capacity, challenge gas, breakthrough time, adsorption isotherms.

\footnotetext{
${ }^{*}$ Corresponding author

E-mail: sidrachm5@gmail.com (SS. Kiani)
} 


\section{Introduction}

34 Due to high adsorptive properties of $\mathrm{AC}$, it has been employed in a huge range of applications as 35 an easy and safe technique for eliminating contaminants from air stream and from water as well.

36 Of the many carbonaceous materials, activated carbon has gained this special property. This is

37 mainly because of porous nature and huge surface area of activated carbon which makes it 38 functional for removal of irritating and toxic gases from the environment. Impregnating activated carbon (IAC) with warily chosen materials, significantly increases its capacity of adsorption for a

40 large number of gases that raw activated carbon is unable to filter. This marvelous property of 41 activated carbon has been used in the manufacturing of canisters and gas mask filters for the last

42 few decades. With the rising concern on environmental pollution, there has been an increased 43 curiosity in ACs as the means for eliminating pollutants from environment (Abdulrasheed, Jalil et 44 al. 2018, Huve, Ryzhikov et al. 2018, Eskandari, Andalib et al. 2020, Cai, Yang et al. 2021, Wen, 45 Liu et al. 2021). Both the Occupational Safety and Health Administration (OSHA) and 46 Environmental Protection Agency (EPA) have considered AC adsorption as the "gold standard" 47 technology for optimum removal of contaminants on the priority list (Wu, Chang et al. 2007, Yang, Lu et al. 2020).

$49 \mathrm{AC}$ is a nice adsorbent for some organic vapors but for polar and low molecular weight gases, it is a poor adsorbent. On the other hand, impregnated ACs which have been modified with chemical 51 reagent react strongly with these kinds of gases, bind them on the surface and thus remove them 52 from airstream (Ho, Moon et al. 2019, Kiani, Faiz et al. 2020, Kiani, Farooq et al. 2021).

53 On the AC surface, pollutant gas molecules can be adsorbed by two approaches, physisorption and 54 chemisorption. Physisorption being a surface phenomenon holds the adsorbate pollutant molecules 55 on the surface of AC by Van der Waal's forces and classical electrostatic interactions. In 
chemisorption, adsorbent and adsorbate pollutant molecules are held together on AC interface by

57 means of chemical bond. In case of unimpregnated AC, molecules attach to the surface of AC only

58 by weak physical forces. Owing to the weakness of these interactions between adsorbate and AC,

59 adsorbate can be released into atmosphere easily causing several ecological concerns (Mahle,

60 Peterson et al. 2010, Muzarpar, Leman et al. 2020).

61 Unimpregnated $\mathrm{AC}$ does not have the capability to remove contaminants from airstream to a

62 greater extent. Therefore, processes have been developed to coat chemicals on the AC surface to

63 provide essential filtering capabilities. In order to improve removal mechanism of gases from

64 airstream, various treatments were used. Most important one of them is the use of organic coatings

65 (Ho, Chun et al. 2019, Khayan, Anwar et al. 2019). Several impregnating materials i.e.

diisopropylamine (DIPA), triethylenediamine (TEDA), piperidine, di-N-propylamine (DNPA),

67 citric acid and tartaric acid have been used for contaminant removal. These "new generation"

68 impregnated ACs can be used for several applications, most important one being used for toxic

69 gases adsorption from air stream. In nuclear testing, most successful combinations to date consist

70 of coal based carbon impregnated with TEDA for the removal of radioactive methyl iodide

71 (González-García, González et al. 2011, Farooq, Irfan et al. 2012, Zhou, Hao et al. 2014, Lee, Lee

72 et al. 2020). In the present work, various types of TEDA impregnated activated carbon samples

73 were prepared by using a very novel and properly developed setup which involves sublimation

74 process for the impregnation of TEDA on activated carbon using Fluidized bed adsorbing tower

75 (FBT). Breakthrough times of IACs were quantified for $\mathrm{SO}_{2}$ as challenge gases. The intention of

76 present study was to assess the adsorption capacity of AC and TEDA impregnated ACs for $\mathrm{SO}_{2}$

77 gas. Concentration of gas was measured by using FTIR based gas analyzer. In addition to IACs,

78 an un-impregnated activated carbon was also tested for gas adsorption capacity. 


\subsection{Materials/Chemicals}

81 Coal based granular AC having surface area $984 \mathrm{~m}^{2} / \mathrm{g}$, total pore volume $0.423 \mathrm{~cm}^{3} / \mathrm{g}$, density 6.7

$82 \mathrm{~g} / \mathrm{cm}^{3}$, moisture content $11 \%$ and $\mathrm{pH}$ value of 7.8 was used. Chemical used for impregnation was

83 triethylenedianine $\left(\mathrm{C}_{6} \mathrm{H}_{12} \mathrm{~N}_{2}\right)$. Leaching agent used was acetonitrile.

$84 \quad 2.2$ Design and Scheme of Pilot Scale Impregnation Setup

85 TEDA was impregnated on AC by using sublimation process. This sublimation process was 86 carried out in a specially designed pilot scale impregnation setup which consists of a fluidized bed 87 adsorbing tower (FBT), TEDA vessel, blower and heat exchanger (HX). These are connected to 88 an electronic control panel (Farooq, Irfan et al. 2012). Design of setup is shown in Fig. 1. Fluidized 89 bed adsorbing tower is the most important part of this setup where TEDA in vapor form 90 impregnates on AC. This technique has the advantage that a uniform impregnant layer can be 91 achieved over all internal and external surfaces of AC. 


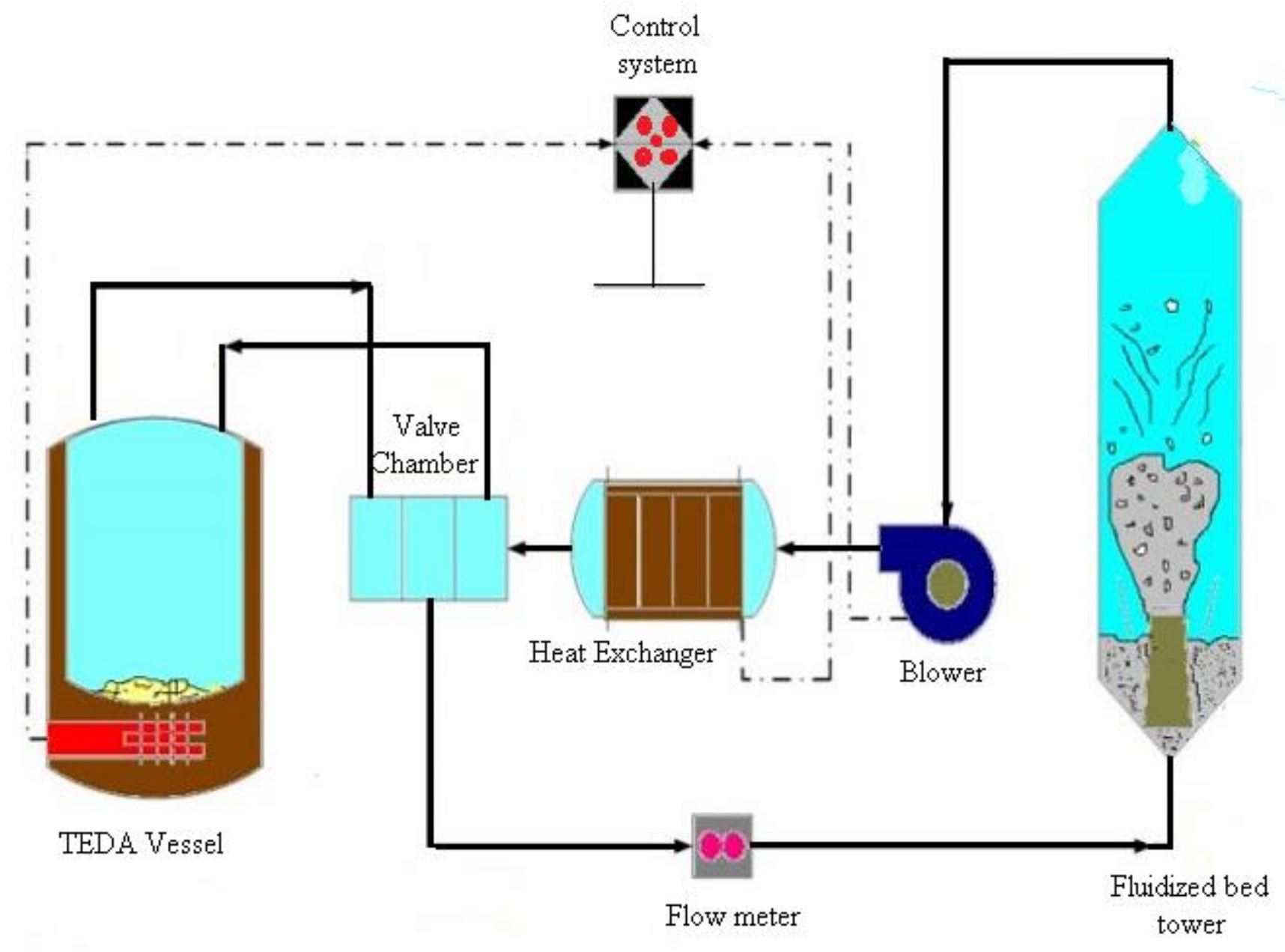

Fig. 1 Experimental setup for TEDA impregnation by sublimation

95 First of all oil present in the $\mathrm{HX}$ is heated by means of heater till it attains $250{ }^{\circ} \mathrm{C}$ temperature.

Blower is then switched on and air moves towards HX. This hot air then travels directly towards

97 FBT. By this manner, air is recirculated till it attains $100{ }^{\circ} \mathrm{C}$ temperature within the FBT. AC bed present inside the FBT is also heated by this hot air. In the meantime, TEDA vessel heater is also operated to attain the temperature of $100{ }^{\circ} \mathrm{C}$ for TEDA sublimation. At this time, valve is opened and $100{ }^{\circ} \mathrm{C}$ air flows into TEDA vessel, carries TEDA vapors from the vessel and then moves to the FBT. As a result of fluidization of AC bed in FBT, each and every particle of AC from all sides 
102 comes in contact with TEDA laden air. So in this manner, TEDA in vapors form gets impregnated 103 on external and internal surfaces of AC. This cycle is repeated for a specified time period until all 104 the TEDA (in the TEDA vessel) is sublimed and gets adsorbed on AC. This method of fluidization 105 and sublimation by using hot air has a number of advantages over other impregnation methods. 106 Here, post drying process of impregnated AC is not needed and this process also ensures uniform 107 impregnation. The samples prepared with various concentration of TEDA are listed in Table 1.

Table. 1 Details of TEDA impregnated ACs

\begin{tabular}{|c|c|c|c|c|c|c|}
\hline Sr. No. & $\begin{array}{c}\text { Sample } \\
\text { Code }\end{array}$ & TEDA \% & $\begin{array}{c}\text { Impregnation } \\
\text { temp. } \\
\left({ }^{\circ} \mathrm{C}\right)\end{array}$ & $\begin{array}{c}\text { TEDA } \\
\text { vessel } \\
\text { temp. }\left({ }^{\circ} \mathrm{C}\right)\end{array}$ & $\begin{array}{l}\text { Activated carbon } \\
\text { Amount (kg) }\end{array}$ & $\begin{array}{l}\text { Time } \\
\text { (hrs) }\end{array}$ \\
\hline 1 & AC-1 & 3.2 & 95 & 90 & 2 & 2 \\
\hline 2 & AC-2 & 4 & 95 & 90 & 2 & 2 \\
\hline 3 & AC-3 & 5.5 & 95 & 90 & 2 & 2 \\
\hline 4 & AC- 4 & 6.5 & 95 & 90 & 2 & 2 \\
\hline 5 & AC-5 & 7.8 & 95 & 90 & 2 & 2 \\
\hline 6 & AC- 6 & 8.5 & 95 & 90 & 2 & 2 \\
\hline 7 & $\mathrm{AC}-7$ & 9.1 & 95 & 90 & 2 & 2 \\
\hline 8 & AC- 8 & 10.3 & 95 & 90 & 2 & 2 \\
\hline
\end{tabular}

109

111 A Hitachi S-4800 SEM was used to image the samples. Beam extraction current of $15 \mu \mathrm{A}$, 112 accelerating voltage $20 \mathrm{kV}$ and working distance of $12 \mathrm{~mm}$ were the characteristic conditions 113 employed. To attain stability and to facilitate imaging, a conducting carbon paste for fixing the 114 granules of AC was used. Magnification used was 30-500x. 
115 Determination of breakthrough time was done by FTIR based GASMET Analyzer. For gas 116 filtration, samples were tested by using sulphur dioxide $\left(\mathrm{SO}_{2}\right)$ as a challenge gas. $0.5 \mathrm{~g}$ of each 117 sample was tested for $\mathrm{SO}_{2}$ gas. These were exposed to 57ppmv challenge gas. Total flow rate 118 comprising $\mathrm{SO}_{2}$ and diluent $\mathrm{N}_{2}$ was $3 \mathrm{~L} / \mathrm{min}$. In dilution chamber, $\mathrm{SO}_{2}$ gets diluted after mixing 119 with $\mathrm{N}_{2}$ and passed through $\mathrm{AC}$ bed for toxic gas adsorption. Breakthrough time ( $\mathrm{t}_{\mathrm{b}}$ ) was measured 120 as the time when challenge gas concentration downstream of AC bed reached a value of $5 \mathrm{ppmv}$. 121 Experimental setup flow chart for $\mathrm{SO}_{2}$ testing is shown in Fig. 2.

122

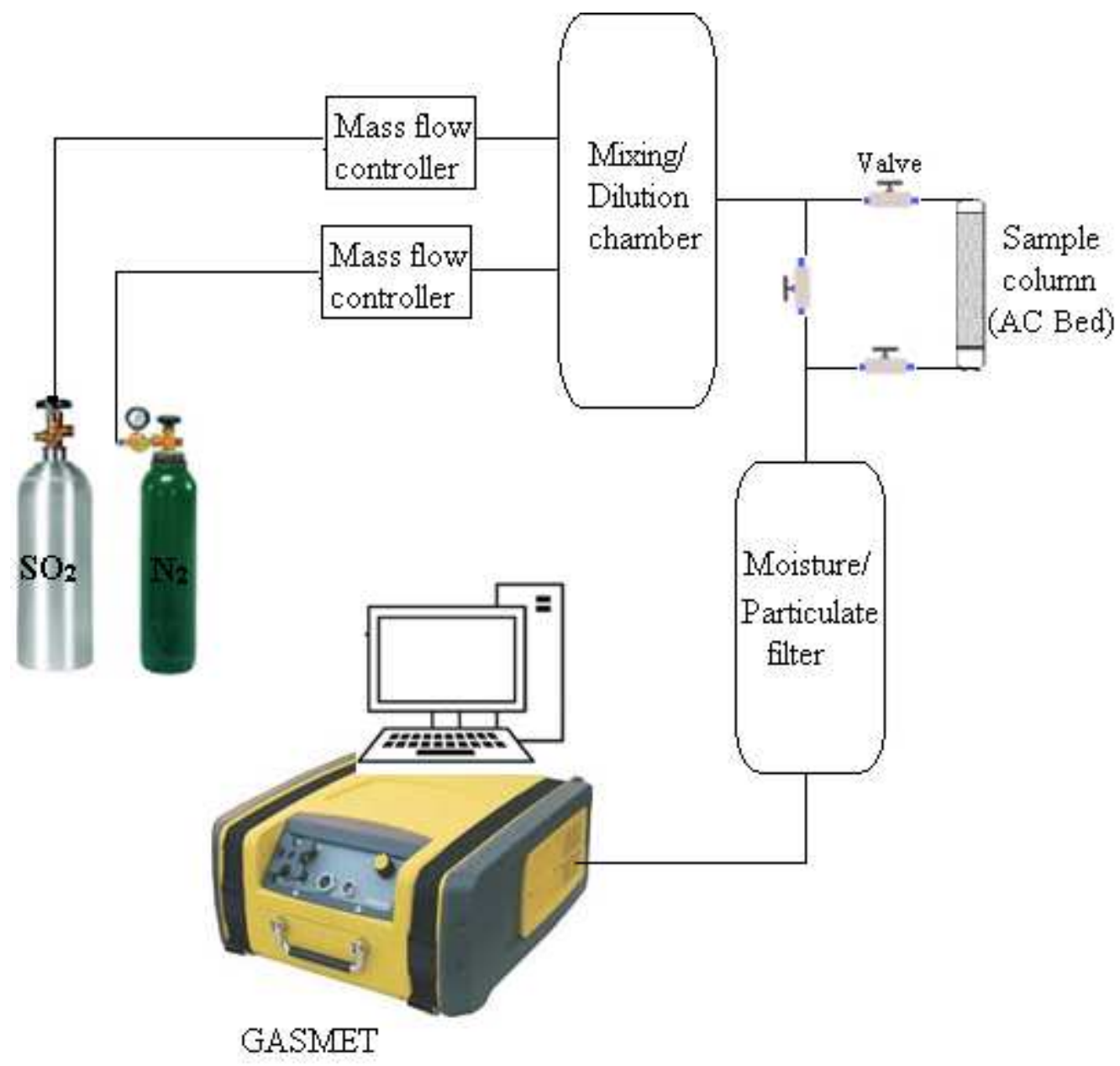

Fig.2 Experimental setup to study $\mathrm{SO}_{2}$ adsorption on $\mathrm{AC}$ 
127 ASTM standard tests were performed to calculate the Particle size distribution, Ball-pan hardness 128 number, Water solubles, Apparent density, Total ash content, Moisture content, Iodine number 129 and $\mathrm{pH}$ of Raw and TEDA impregnated activated carbon sample (ASTM 1996).

131 Experimentally, adsorption capacity was calculated by using breakthrough time curve data by 132 subtracting the area below the breakthrough time curve from the total area. This final area above 133 the curve gives value of adsorption capacity. Area below breakthrough curve was calculated by 134 integration method. Theoretically, breakthrough time was determined by using modified Wheeler 135 Jonas equation and this equation is written as:

$$
\frac{t_{x}}{t_{0.05}}=1-\frac{F}{V K_{v}} \ln \left(\frac{C_{o}-C_{x}}{C_{x}}\right)
$$

Where, $t_{x}$ is the breakthrough time $(\mathrm{min}), t_{0.05}$ is saturation time $(\mathrm{min}), F$ is total flow rate $\left(\mathrm{cm}^{3} / \mathrm{min}\right), V$ is volume of packed bed $\left(\mathrm{cm}^{3}\right), K_{v}$ is adsorption rate constant $\left(\mathrm{min}^{-1}\right), C_{o}=$ inlet gas concentration $\left(\mathrm{gm} / \mathrm{cm}^{3}\right)$ and $C_{x}$ is the concentration at time $t_{x}\left(\mathrm{gm} / \mathrm{cm}^{3}\right)$.

\subsection{Adsorption isotherms}

137 The adsorption data of $\mathrm{SO}_{2}$ on $\mathrm{AC}$ was subjected to three adsorption models i.e. Langmuir, 138 Freundlich and Dubinin-Radushkevich (D-R). Langmuir isotherm was applied in the following 139 linearized form (Lua and Guo 2001):

$$
\frac{C_{e}}{C_{a d s}}=\frac{1}{Q b}+\frac{C_{e}}{Q}
$$


$141 C_{e}$ is the equilibrium concentration of gas $\left(\mathrm{SO}_{2}\right)$ in ppm, $C_{a d s}$ is the adsorbed concentration of gas

142 on activated carbon in ppm. $Q$ is the constant which signifies maximum adsorption capacity at

143 monolayer formation and $b$ is the characteristic Langmuir constant for the adsorption system.

144 Freundlich adsorption isotherm was applied in the following linearized form (Lua and Guo 2001):

145

$$
\ln q_{e}=\ln K_{f}+\frac{1}{n} \ln C_{e}
$$

$146 q_{e}$ is the amount of gas adsorbed, $C_{e}$ is the equilibrium concentration of gas, $K_{f}$ is the Freundlich

147 rate constant and $\frac{1}{n}$ is Freundlich adsorption constant strength.

148 D-R adsorption isotherm was applied in the following linearized form (Lua and Guo 2001):

$$
\ln q_{e}=\ln q_{s}-K_{D} \varepsilon^{2}
$$

150 Where $q_{s}$ is the constant in D-R isotherm which is related to adsorption capacity, $K_{D}$ is constant 151 related to mean free energy of adsorption and $\mathcal{E}$ is the Polanyi potential which is given by:

$$
\varepsilon=R T \ln \left(1+1 / C_{e}\right)
$$

153 Where $R$ is gas constant, $T$ is absolute temperature and $C_{e}$ is equilibrium concentration of gas.

155 Mass transfer phenomenon can be best understood by its thermodynamics and kinetics. Pseudo 156 first order and second order models were applied to analyze the adsorption data for kinetic study. 157 Pseudo first order model is the simplest equation which relates dependence of adsorption rate on 158 adsorption capability. Equation is written as (Sumathi, Bhatia et al. 2010):

$$
\frac{d q}{d t}=k_{1}\left(q_{e}-q_{t}\right)
$$


160 Linearized form is given as:

161

$$
\log \left(q_{e}-q_{t}\right)=\log q_{e}-K_{1} 2.303 t
$$

$162 q_{e}$ and $q_{t}$ are the amounts of gas adsorbed at equilibrium and at time "t" respectively, $K_{1}$ is rate 163 constant of pseudo first order and $t$ is contact time.

164 Equation for pseudo second order model is written as:

165

$$
\frac{d q}{d t}=K_{2}\left(q_{e}-q_{t}\right) 2
$$

166 Linearized form is given as:

167

$$
\frac{t}{q_{t}}=\frac{1}{K_{2} q_{e}}+\frac{t}{q_{e}}
$$

168 Where $t$ is time in min and $q / t$ is the amount of gas adsorbed at timet, $K_{2}$ is rate constant of pseudo 169 second order reaction and $q_{e}$ is equilibrium adsorption capacity.

171 The primary thermodynamic parameters which are used to calculate the probability and 172 spontaneity of adsorption process are change of enthalpy $(\Delta \mathrm{H})$, change of entropy $(\Delta \mathrm{S})$ and free 173 energy change $(\Delta \mathrm{G})$. Following equations can be used to predict these parameters (Myers 2002):

$$
\Delta G=-R T \ln K_{d}
$$

$175 R$ is gas constant, $T$ is absolute temperature and $K_{d}$ is distribution coefficient and is calculated by 176 following equation.

$$
K_{\mathrm{d}}=(C o-C e) /(m s / V) C e
$$


178 Value of entropy change and enthalpy change was analyzed from intercept and slope of plot

179 between $\ln K_{d}$ verses $1 / T_{\text {respectively. }}$

\section{Results and Discussion}

181 Comparison of ASTM standard test results of Raw AC and AC-4 was made and shown in Table

2. Results clearly indicate that AC-4 showed an enhancement in properties as compared to the Raw

AC. This is mainly because of the impregnant which imparts these improved properties (Al-Qodah and Shawabkah 2009). So we can say that the prepared AC-4 sample might be a sustainable candidate for purification of noxious gases from atmosphere.

Table 2 ASTM standard tests for Raw AC and AC-4

\begin{tabular}{ccc}
\hline ASTM Standard Tests & Raw AC & AC-4 \\
\hline Mean Particle Size (mm) & 0.77 & 0.88 \\
Ball Pan Hardness Number & 91.9 & 94 \\
Water Solubles (\%) & 0.01 & 0.35 \\
Apparent Density (gm/cm $\left.{ }^{3}\right)$ & 0.41 & 0.43 \\
Total Ash Content (wt. \%) & 5 & 5.5 \\
Moisture Content (wt. \%) & 19.5 & 0.85 \\
Iodine Number (mg/g-C) & 920 & 1031 \\
Ph & 7.8 & 9.54 \\
\hline
\end{tabular}

188 SEM analysis was done to study the distribution of TEDA on AC surface. Fig. 3 (a) and (b) show 189 SEM images of Raw AC at different magnifications which represent cracks and cavities on surface 190 representing a system of complex porous network. Impregnation results in blocking of cavities and 191 cracks and clogging of pore openings (Kiani, Faiz et al. 2020). Fig. 3(c), (d), (e), (f), (g) and (h) 192 represent the distribution of different concentrations of TEDA on surface of AC-1, AC-3, AC-4, 
193 AC-5, AC-7 and AC-8. In all these images, it can be seen that the AC surface is immensely covered 194 with TEDA impregnants. Better the distribution of TEDA on surface, better will be its capability 195 to react with toxic gases in atmosphere by adsorbing them on the surface of AC by means of 196 chemical bond with the impregnant. Apart from the chemical adsorption of gases on AC, some 197 pores are also available on $\mathrm{AC}$ which are responsible for physical adsorption of gases (Wu, Chang 198 et al. 2007, Arcibar-Orozco, Rangel-Mendez et al. 2013). As TEDA is basic in nature, it plays a 199 significant role in the removal of acidic gases like $\mathrm{SO}_{2}$ from air.
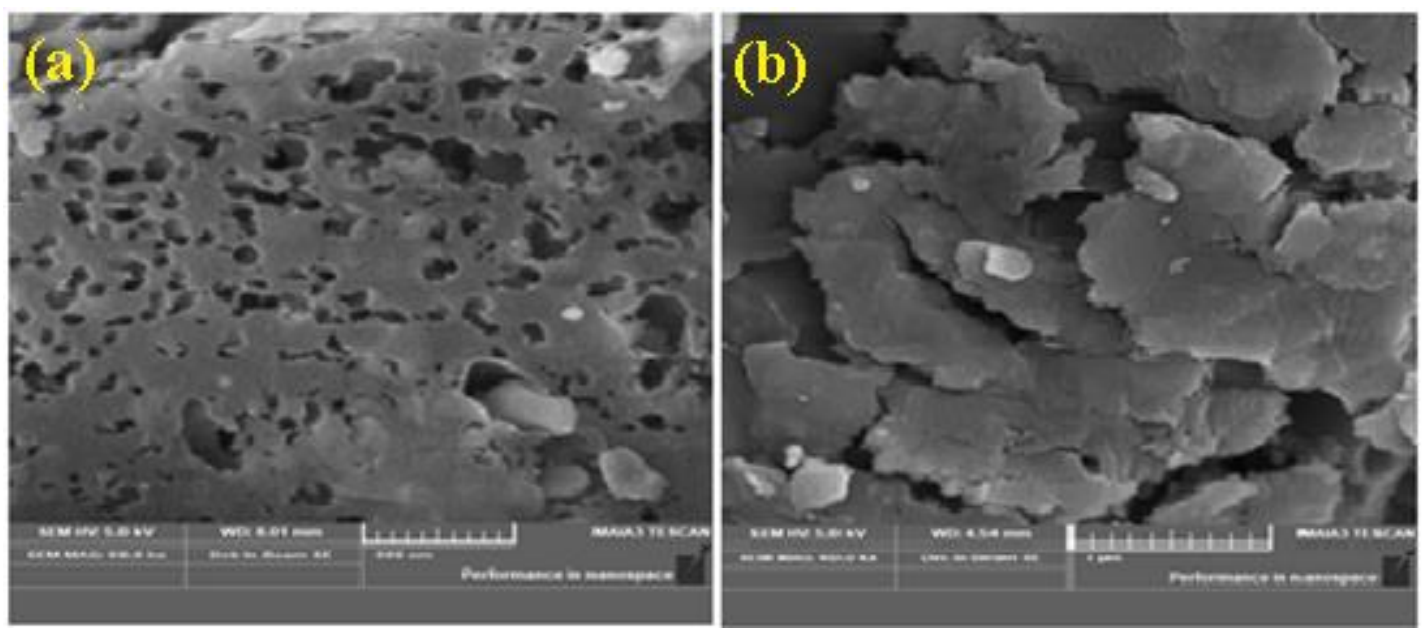

Fig. 3(a) SEM images of Raw AC at (a) 60kx and (b) 50kx 

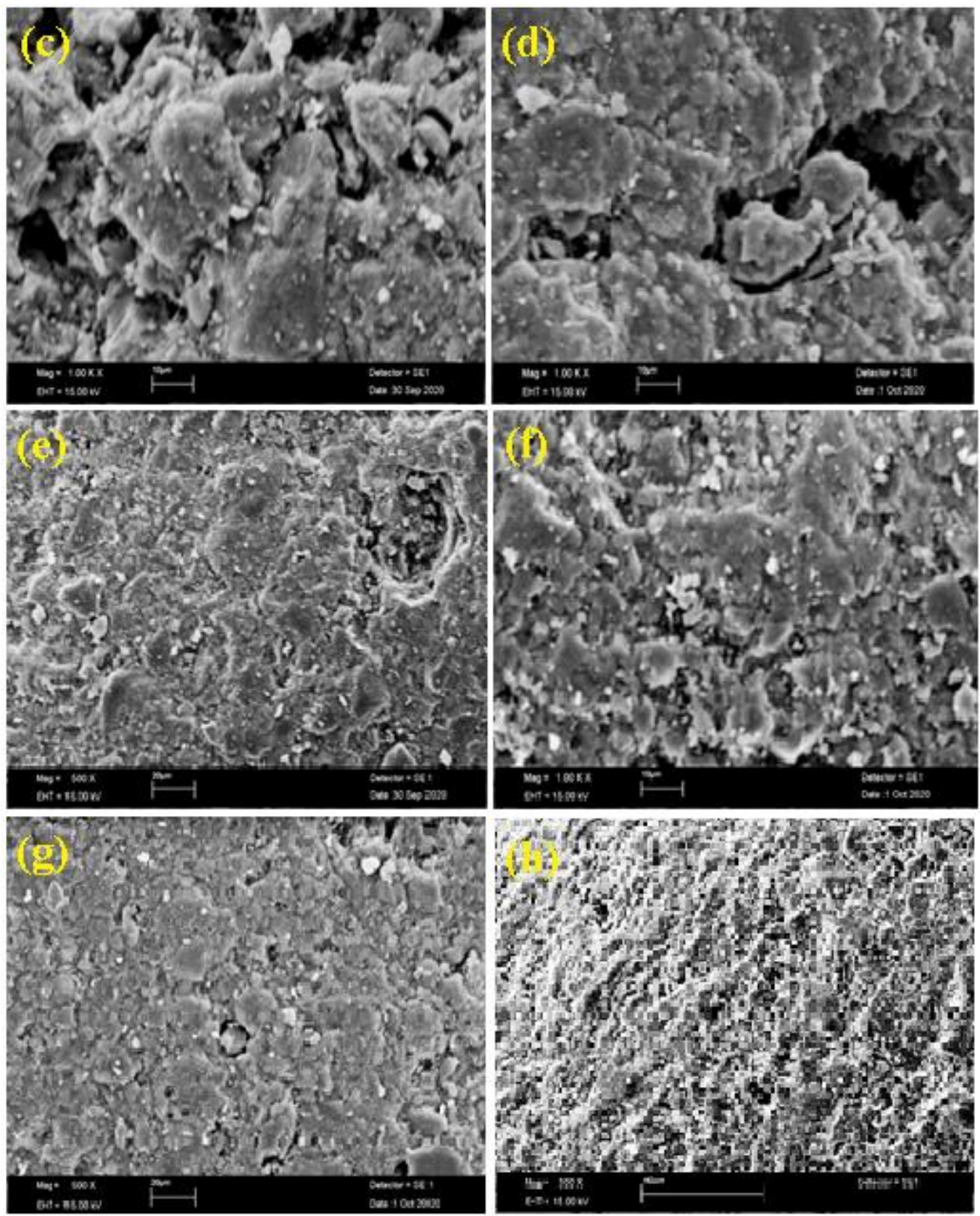

205 Fig. 3(b) SEM images of impregnated ACs (c): (AC-1), (d): (AC-3), (e): (AC-4), (f): (AC-5), (g): (AC-7) and (h):

$207 \mathrm{pH}$ of samples was measured by ASTM-D3838 method and results are presented in Fig. 4. Results

208 clearly show that as we increase the amount of TEDA, pH value of ACs also increases. This is due

209 to the fact that TEDA is basic in nature and its impregnation makes AC more basic. This increased 
210 basicity of adsorbent (by means of basic adsorbent) is highly desirable for the chemical adsorption

211 of acidic gases as it leads to the filtration of acidic gases from contaminated environment more

212 efficiently (Wu, Chang et al. 2007).

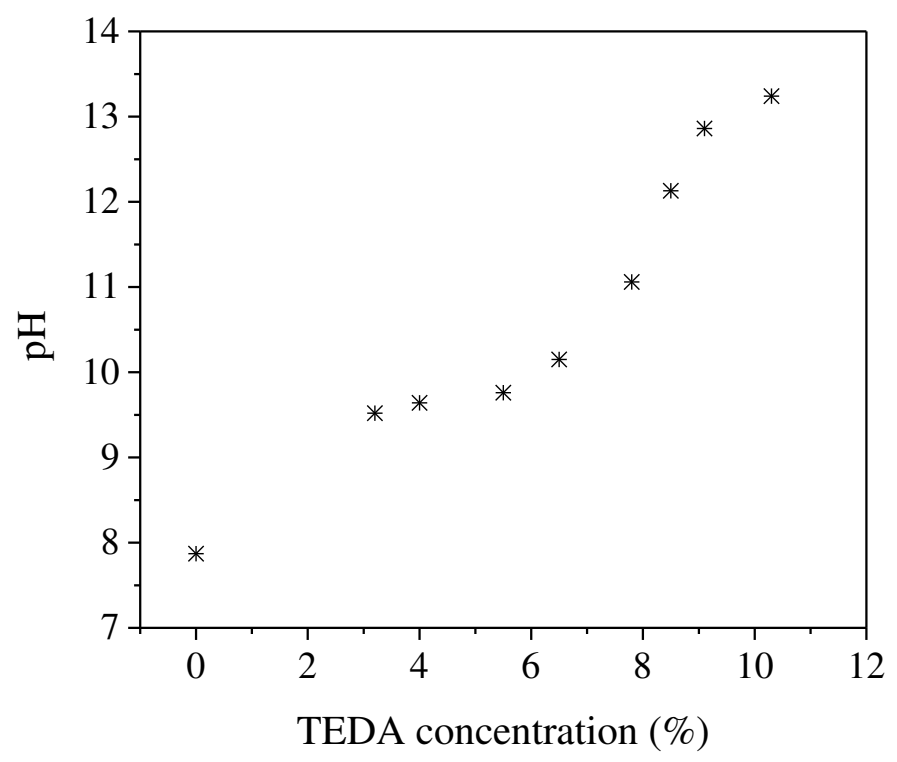

Fig. 4 pH of TEDA impregnated AC samples

216 Gas filtration capability was tested for $\mathrm{SO}_{2}$ gas. Comparison of breakthrough time was made

217 between the raw and various TEDA impregnated ACs and shown in Fig. 5(a) and 5(b). These

218 results indicated that Raw AC showed less breakthrough time i.e. $11.6 \mathrm{~min}$ as compared to other

219 impregnated samples and so responsible for the purification of toxic gases to lesser extent. In case

220 of TEDA impregnated samples breakthrough time increases initially with the increase in

221 concentration of TEDA but after a certain limit of impregnation, breakthrough time decreases with

222 further increasing the concentration and is shown in Fig. 5(c). The reason behind this is the

223 blocking of pore mouths. Impregnation beyond a certain limit results in the blockage of AC pores

224 and gas molecules do not find more available sites for adsorption, hence its breakthrough time 
225 decreases considerably (Wu, Chang et al. 2007, Bobbitt, Mendonca et al. 2017). After 7\% TEDA

226 impregnation, a considerable decrease in breakthrough time was observed. Breakthrough time of

227 AC-1, AC-2, AC-3, AC-4, AC-5, AC-6, AC-7 and AC-8 is 160, 191, 247, 264, 234, 222, 220 and

228211 minutes respectively. Breakthrough time of AC-4 is almost 25 times greater than Raw AC.

$229 \mathrm{SO}_{2}$ adsorption was supposed to occur through subsequent paths (Kiani, Faiz et al. 2020):

230

231

232
For Raw AC:

$\mathrm{AC}+\mathrm{SO}_{2} \rightarrow \mathrm{AC}-\mathrm{SO}_{2}$

For sample:

$$
\mathrm{C}_{6} \mathrm{H}_{12} \mathrm{~N}_{2}+2 \mathrm{SO}_{2}
$$$$
\text { ( }
$$

$$
\rightarrow \mathrm{SO}_{2}-\mathrm{NC}_{6} \mathrm{H}_{12} \mathrm{~N}-\mathrm{O}_{2} \mathrm{~S}
$$

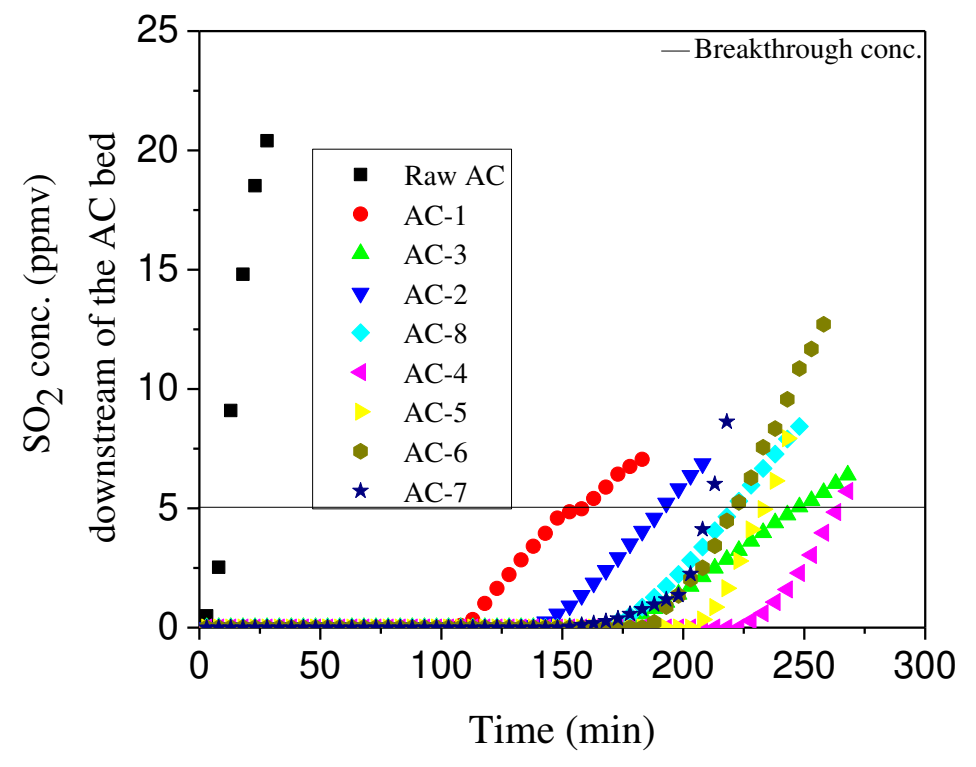

Fig. 5(a) Breakthrough time curves of TEDA impregnated samples for $57 \mathrm{ppmv} \mathrm{SO}_{2}$ as challenge gas 


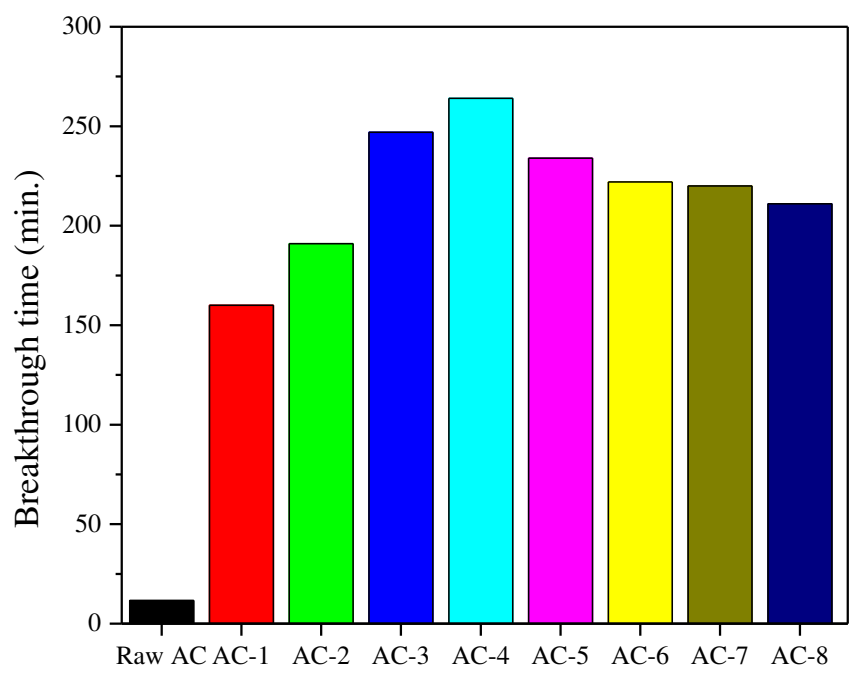

Raw $\mathrm{AC}$ and TEDA Impregnated Samples

Fig. 5(b) Comparison of breakthrough time of TEDA Impregnated samples (at $5 \mathrm{ppmv}$ ) for $\mathrm{SO}_{2}$ gas

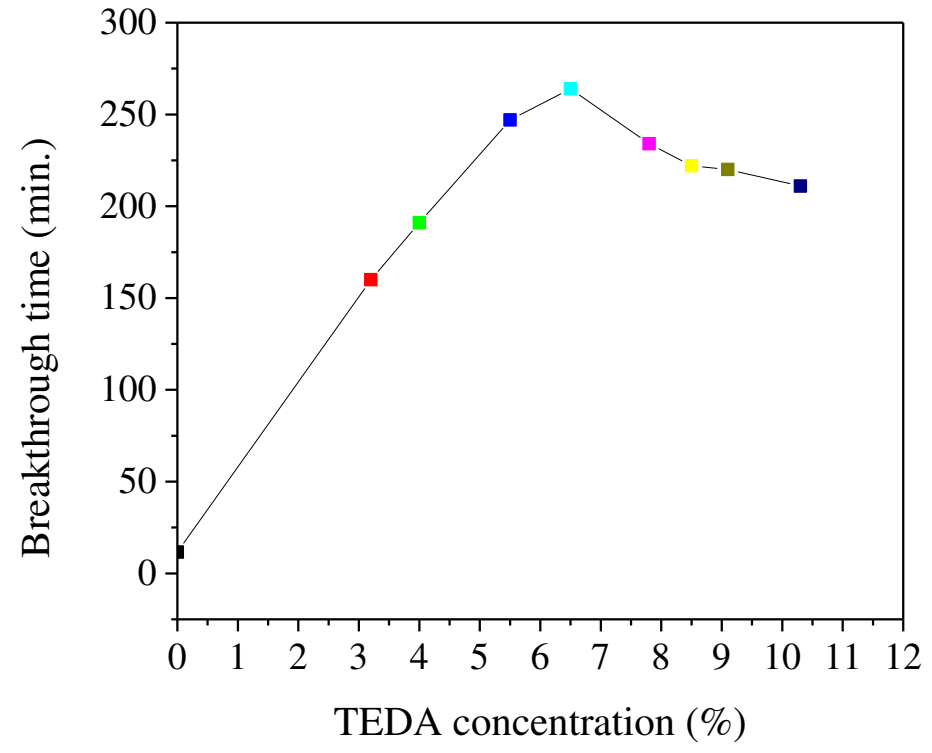

Fig. 5(c) Relation between breakthrough time and TEDA concentration

243 Adsorption capacity of Raw $\mathrm{AC}$ was found to be $0.41 \mathrm{gSO}_{2} / \mathrm{g}-\mathrm{C}$ whereas all other impregnated 244 samples showed higher adsorption capacities. Maximum adsorption capacity was observed for 
245 AC-4 which is about 10 times higher than Raw AC as shown in Table. 3. The order of adsorption 246 capacities of samples was found as Raw AC<AC-1<AC-2<AC-8<AC-7<AC-6<AC-3<AC$2475<\mathrm{AC}-4$ for $\mathrm{SO}_{2}$ gas. Impregnation of TEDA on AC surface might be responsible for a greater 248 resistance or reaction sites (Mahle, Peterson et al. 2010, Perera, Ranjith et al. 2012, Zhou, Su et al. 249 2018, Hyuncheol Lee 2019).

250

251

252

253

254

255

256

257

258

259 Table 4 shows breakthrough time of samples calculated by using modified Wheeler Jonas

260 equation. A plot of $\frac{t_{x}}{t_{0.05}} \mathrm{vs} \ln \left(\frac{C_{o}-C_{x}}{C_{x}}\right)$ gives a straight line with slope equal to $\frac{F}{V K_{v}}$ and intercept 1

261 (Zhou, Feng et al. 2011). Breakthrough time calculated by this method showed almost the same

262 trend as exhibited by the experimental method, although, the calculated breakthrough times are 263 slightly on higher side as compared to the experimental ones. 


\begin{tabular}{cc}
\hline $\begin{array}{l}\text { Sample } \\
\text { Code }\end{array}$ & $\begin{array}{c}\text { Calculated } \\
\text { Breakthrough } \\
\text { Time (min.) }\end{array}$ \\
\hline Raw AC & 18 \\
AC-1 & 198 \\
AC-2 & 241 \\
AC-3 & 264 \\
AC-4 & 290 \\
AC-5 & 259 \\
AC-6 & 277 \\
AC-7 & 262 \\
AC-8 & 249 \\
\hline
\end{tabular}

272

273

274

275 Fig. 6 shows comparison of breakthrough time calculated by both methods. It can be seen that 276 experimental and model results are linearly varying, but the model breakthrough time is slightly 277 greater than experimental breakthrough time (Lodewyckx, Wood et al. 2004). The reason is that 278 theoretical equations always over predict physical quantities. The regression value is 0.97 which 279 shows a good linear fit between model and experimental results. 


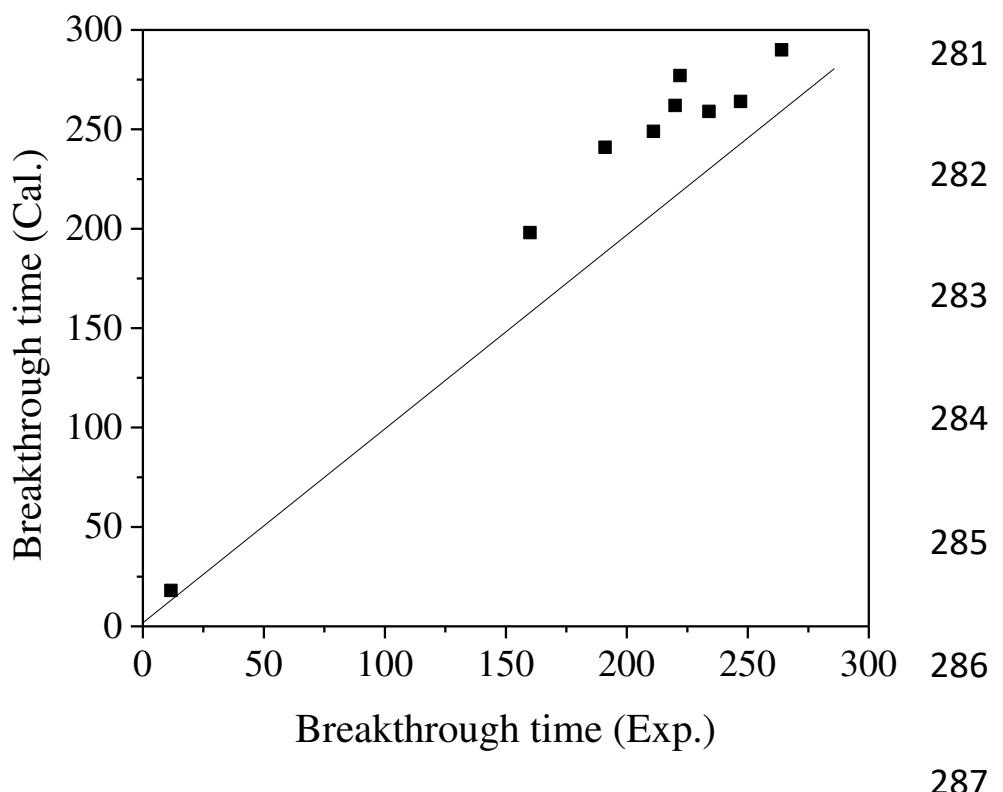

Fig. 6 Plot of Experimental and Model breakthrough time

291 Fig. 7 shows plot of $\mathrm{C}_{\mathrm{e}} / \mathrm{C}_{\mathrm{ads}}$ vs $\mathrm{C}_{\mathrm{e}}$ for $\mathrm{SO}_{2}$ on $\mathrm{AC}-4$ with initial concentration 57 ppm at $298 \mathrm{~K}$.

292 From the intercept and slope of this plot, values of Langmuir parameters are estimated for the

293 system. Value of $\mathrm{R}^{2}$ determines the favorability of adsorption process and its corresponding data

294 is given in Table 5. Langmuir isotherm considers that the ions remain adsorbed on certain sites

295 that are mono-energetic and each site binds only one adsorbate molecule without any interaction

296 with the neighboring ions. Moreover, it supports the monolayer adsorption of gas on substrate (Lua 297 and Guo 2001). 


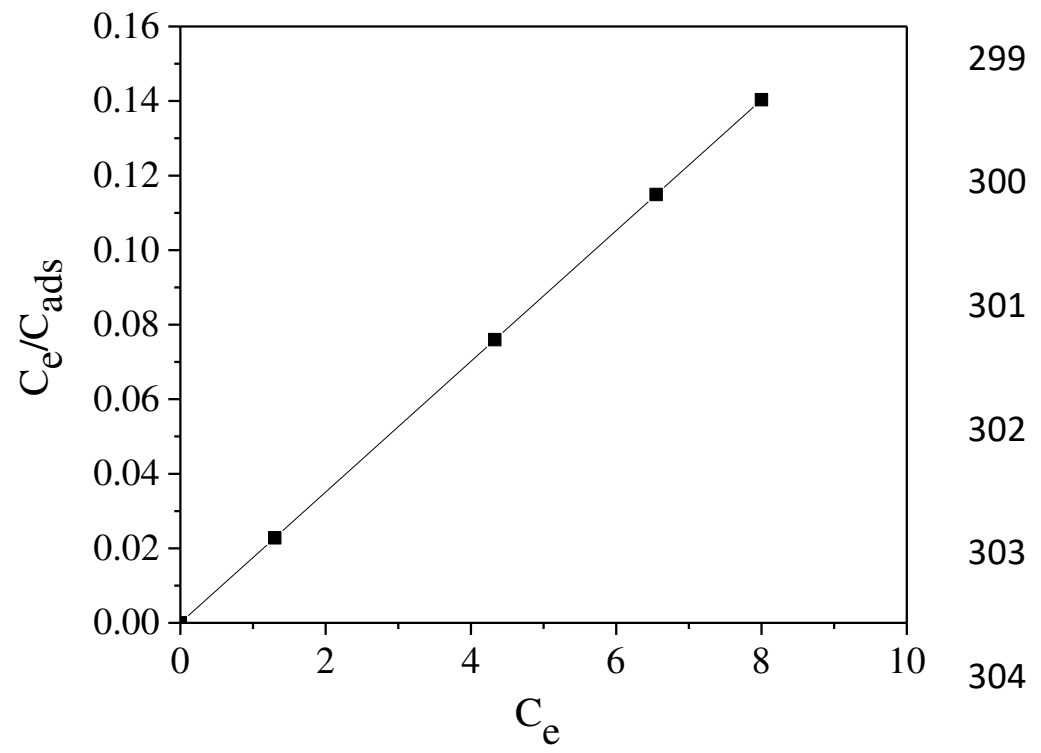

Fig. 7 Langmuir plot of $\mathrm{SO}_{2}$ adsorption on $\mathrm{AC}-4$

307 Fig. 8 shows the plot of $\operatorname{lnC}_{\mathrm{e}}$ vs $\operatorname{lnq}_{\mathrm{e}}$ for the adsorption data of $\mathrm{SO}_{2}$ gas on $\mathrm{AC}-4$ at initial 308 concentration of $57 \mathrm{ppm}$ and $298 \mathrm{~K}$. Slope and intercept were used to determine the Freundlich 309 constant (Muzarpar, Leman et al. 2020). Value of $\mathrm{R}^{2}$ determines the favorability of adsorption 310 process and its corresponding data is given in Table 5. 


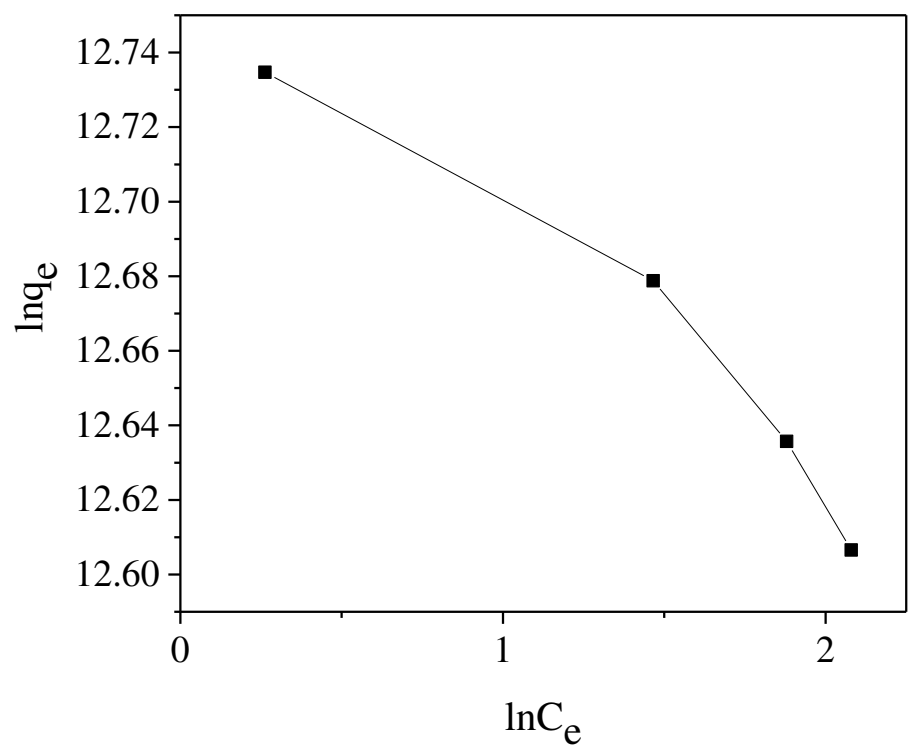

312

Fig. 8 Freundlich plot of $\mathrm{SO}_{2}$ adsorption on $\mathrm{AC}-4$

314 Fig. 9 shows the plot of $\operatorname{lnC}_{\text {ads }}$ vs $\varepsilon^{2}$ for adsorption data of toxic gas on AC-4 surface at initial 315 concentration of $57 \mathrm{ppm}$ and $298 \mathrm{~K}$. From intercept and slope of plot we get value of D-R 316 parameters (Sumathi, Bhatia et al. 2010). $\mathrm{R}^{2}$ value provides information about the favorability of 317 adsorption process. Fig. 9 shows D-R isotherm plot and its corresponding data is given in Table 5. 


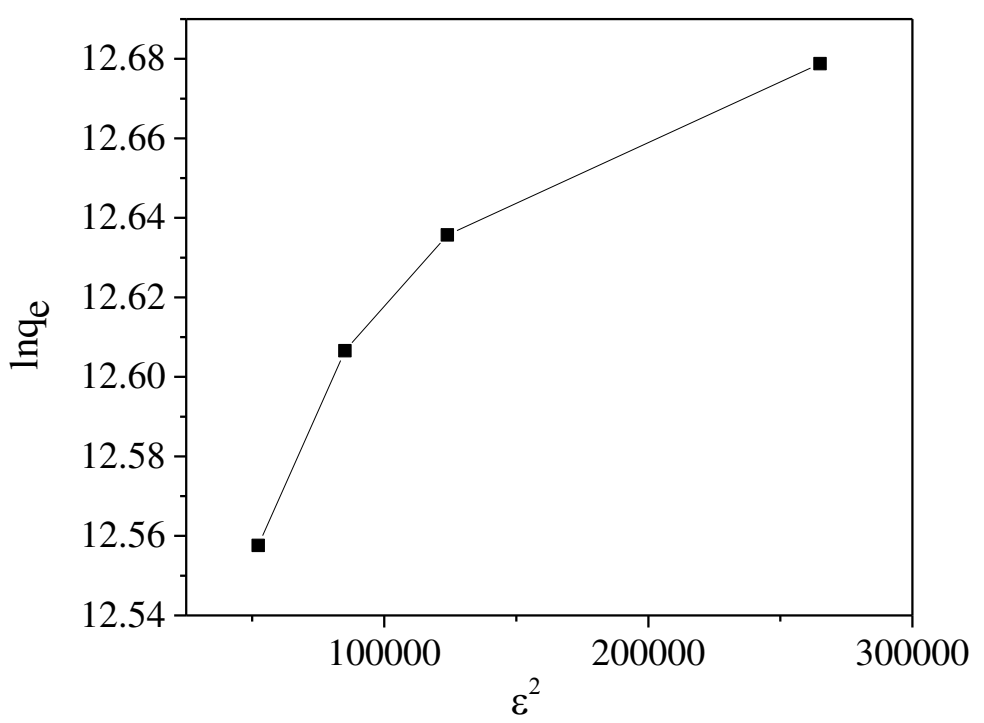

318

Fig. 9 D-R plot of $\mathrm{SO}_{2}$ adsorption on AC-4

\section{Adsorption Kinetics}

321 Plot of $\log \left(\mathrm{q}_{\mathrm{e}}-\mathrm{q}_{\mathrm{t}}\right)$ vs $\mathrm{t}$ for pseudo first order reaction is shown in Fig. 10 and plot of $\mathrm{t} / \mathrm{q}_{\mathrm{t}}$ vs $\mathrm{T}$ for

322 pseudo second order reaction is shown in Fig. 11 for the adsorption of $\mathrm{SO}_{2}$ gas on AC-4. Kinetics

323 of adsorption can be predicted from the corresponding value of $\mathrm{R}^{2}$ (Yi, Wang et al. 2014). Value

324 of $\mathrm{R}^{2}$ for pseudo first order reaction is 0.7223 and for second order is 1 . This concludes that pseudo

325 second order reaction is the most favorable path for adsorption of $\mathrm{SO}_{2}$ on $\mathrm{AC}-4$ and fits best to 326 adsorption process (Sumathi, Bhatia et al. 2010). 


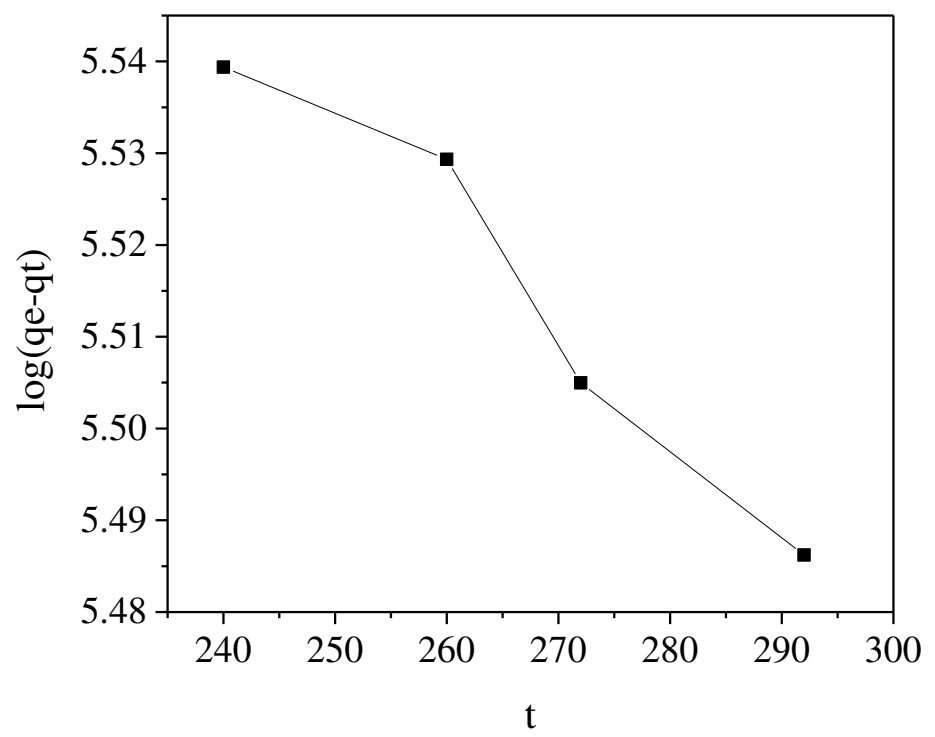

328

Fig. 10 Plot of pseudo first order for $\mathrm{SO}_{2}$ adsorption on AC-4

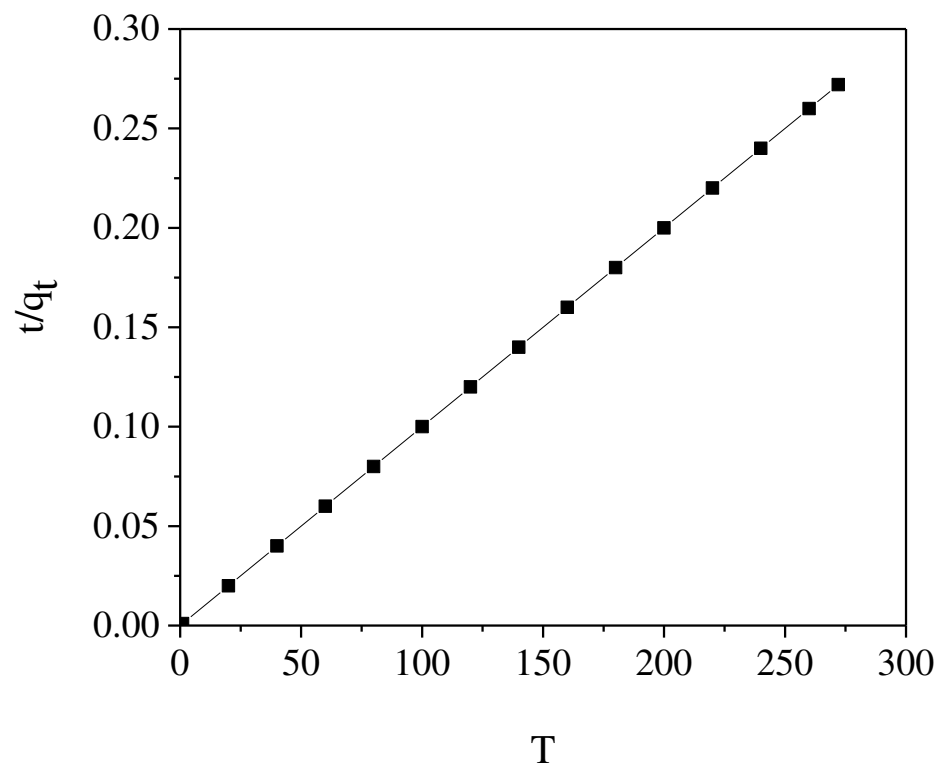

330

331

Fig. 11 Plot of pseudo second order for $\mathrm{SO}_{2}$ adsorption on $\mathrm{AC}-4$ 
333 Plot of $\ln K_{d}$ vs $1 / \mathrm{T}$ is shown in Fig. 12. From the slope and intercept of this graph value of $\Delta G$ and $334 \Delta H$ have been computed respectively. Positive value of $\Delta S$ proposed an increased randomness at 335 the interface in the adsorption process. Positive enthalpy value shows the endothermic reaction 336 while negative free energy indicates the spontaneous nature of adsorption process respectively 337 (Zhou, Yi et al. 2012). Corresponding values are shown in Table 5. Comparison of three isotherm 338 models shows that Langmuir adsorption isotherm model is the best fitted model as compared to 339 Freundlich and D-R isotherms.

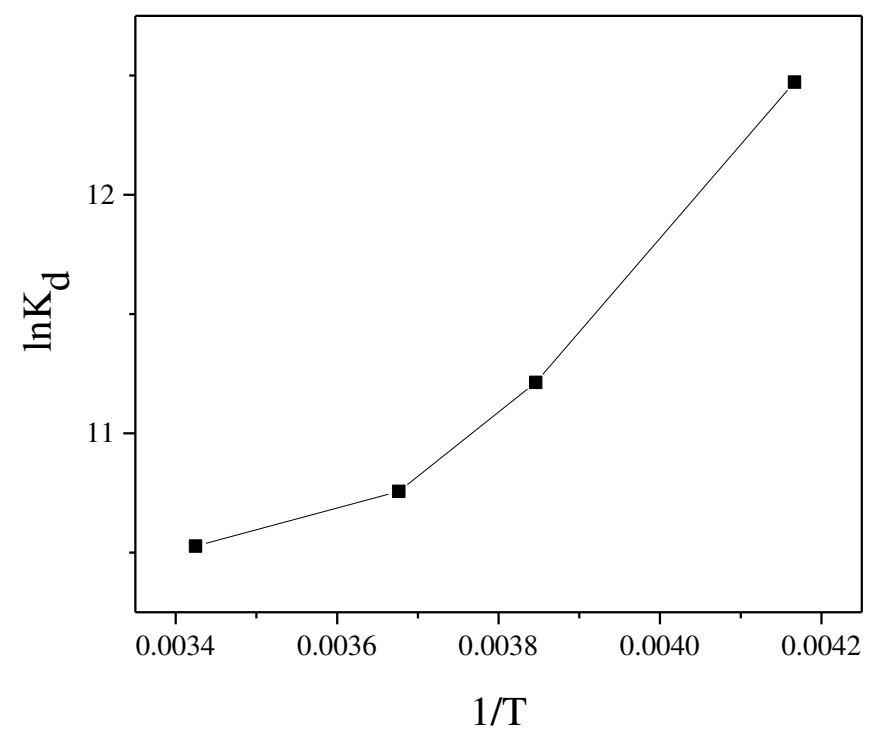

Fig. 12 Plot of $\operatorname{lnKd}$ vs $1 / \mathrm{T}$ for thermodynamic parameters

Table 5 Parameters for Langmuir, Freundlich and D-R isotherms for $\mathrm{SO}_{2}$ adsorption

\begin{tabular}{ccccccc}
\hline Gas adsorbed & Models & \multicolumn{2}{c}{ Parameters } & $\begin{array}{c}\Delta \mathrm{H} \\
\left(\mathrm{kJmol}^{-1}\right)\end{array}$ & $\begin{array}{c}\Delta \mathrm{S} \\
\left(\mathrm{JK}^{-1} \mathrm{~mol}^{1}\right)\end{array}$ & $\begin{array}{c}\Delta \mathrm{G} \\
\left(\mathrm{kJmol}^{-1}\right)\end{array}$ \\
\hline & & $\mathrm{Q}$ & 0.017 & & & \\
& Langmuir & $\mathrm{B}$ & 0 & & & \\
& & $\mathrm{R}^{2}$ & 1 & & & \\
& & $\mathrm{~K}_{\mathrm{f}}$ & 12.7 & & & \\
$\mathrm{SO}_{2}$ & Freundlich & $1 / \mathrm{n}$ & -0.057 & 6628.2 & 9.42 & -26.08 \\
& & $\mathrm{R}^{2}$ & 0.941 & & &
\end{tabular}




\begin{tabular}{ccc} 
& $\mathrm{q}_{\mathrm{s}}$ & 2.5 \\
$\mathrm{D}-\mathrm{R}$ & $\mathrm{K}_{\mathrm{D}}$ & $5 \times 10^{-7}$ \\
& $\mathrm{R}^{2}$ & 0.864 \\
\hline
\end{tabular}

\section{Conclusion}

344 In this study different TEDA impregnated ACs were prepared by using sublimation method. All 345 samples displayed higher breakthrough times and gas adsorption capacities to a considerable 346 amount as compared to the Raw AC. Moreover, AC-4 prepared in this work is a sustainable 347 candidate for the purification of toxic gases from contaminated air by chemisorption on porous 348 carbon surface. Its breakthrough time and adsorption capacity was found to be 264 minutes and

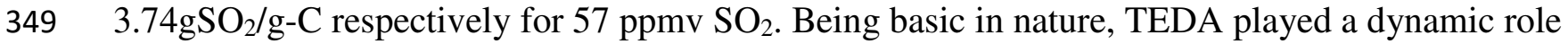
350 in the purification of acidic gases from air. Gas adsorption data are reliable with Langmuir, 351 Freundlich and D-R isotherms. Adsorption data strongly follow Langmuir adsorption isotherm and 352 pseudo second order kinetics. Thermodynamic parameters $\Delta \mathrm{H}, \Delta \mathrm{G}$ and $\Delta \mathrm{S}$ have been calculated. 353 However the positive enthalpy change showed the endothermic reaction for adsorption of $\mathrm{SO}_{2}$ on 354 AC. While negative free energy change confirmed the spontaneous nature of adsorption process.

355 Ethics approval and consent to participate

356 Not applicable

357 Consent for publication

358 Not applicable

359 Availability of data and materials

360 Not applicable

361 Declaration of competing interest 
362 The authors declare no competing financial interest.

\section{$363 \quad$ Funding}

364 This research did not receive any specific grant from funding agencies in the public, commercial 365 or not-for-profit sectors.

\section{Author contribution}

367 Sidra Shaoor Kiani: Literature review, Writng original manuscript

368 Atif Ullah: Experimentation

369 Amjad Farooq: Reagents and other analysis tools, Methodology, Validation, Investigation,

370 Formal analysis, Reviewing manuscript

371 Naseem Irfan: Instrumentation

372 Masroor Ahmed: Instrumentation

373 Mohsan Nawaz: Conceptualization

374 References

375 Abdulrasheed, A., et al. (2018). "Surface modification of activated carbon for adsorption of SO2 376 and NOX: A review of existing and emerging technologies." Renewable and Sustainable Energy $377 \quad$ Reviews 94: 1067-1085.

378 American Society for Testing and Materials (ASTM) Refractories, Carbon and Graphite Products;

379 Activated Carbons,. (1996). West Conshohocken.

380 Al-Qodah, Z. and R. Shawabkah (2009). "Production and characterization of granular activated 381 carbon from activated sludge." Brazilian Journal of Chemical Engineering 26(1): 127-136.

382 Arcibar-Orozco, J. A., et al. (2013). "Reactive adsorption of SO2 on activated carbons with 383 deposited iron nanoparticles." Journal of Hazardous Materials 246: 300-309. 
384 Bobbitt, N. S., et al. (2017). "Metal-organic frameworks for the removal of toxic industrial 385 chemicals and chemical warfare agents." Chemical Society Reviews 46(11): 3357-3385.

386 Cai, Y., et al. (2021). "Hydrothermal-ultrasonic synthesis of $\mathrm{CuO}$ nanorods and CuWO4 387 nanoparticles for catalytic reduction, photocatalysis activity, and antibacterial properties." $388 \quad$ Materials Chemistry and Physics 258: 123919.

389 Eskandari, L., et al. (2020). "Facile colorimetric detection of $\mathrm{Hg}$ (II), photocatalytic and 390 antibacterial efficiency based on silver-manganese disulfide/polyvinyl alcohol-chitosan 391 nanocomposites." International Journal of Biological Macromolecules 164: 4138-4145.

392 Farooq, A., et al. (2012). Impregnation of TEDA onto Activated Carbon at Pilot Scale Level.

393 González-García, C., et al. (2011). "Removal efficiency of radioactive methyl iodide on TEDA394 impregnated activated carbons." Fuel processing technology 92(2): 247-252.

395 Ho, K., et al. (2019). "Design of highly efficient adsorbents for removal of gaseous methyl iodide 396 using tertiary amine-impregnated activated carbon: Integrated experimental and first-principles 397 approach." Chemical Engineering Journal 373: 1003-1011.

398 Ho, K., et al. (2019). "Adsorptive removal of gaseous methyl iodide by triethylenediamine 399 (TEDA)-metal impregnated activated carbons under humid conditions." Journal of Hazardous $400 \quad$ Materials 368: 550-559.

401 Huve, J., et al. (2018). "Porous sorbents for the capture of radioactive iodine compounds: a

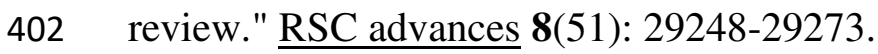

403 Hyuncheol Lee, K. K., Dooyong Lee, Haksu Kim, Chorong Kim (2019). "The Effect of Toxic 404 Gases on TEDA Impregnated Activated Carbon." 2019: 420-420. 
405 Khayan, K., et al. (2019). "Active carbon respiratory masks as the adsorbent of toxic gases in 406 ambient air." Journal of toxicology 2019.

407 Kiani, S. S., et al. (2020). "Synthesis and adsorption behavior of activated carbon impregnated 408 with ASZM-TEDA for purification of contaminated air." Diamond and Related Materials: 107916.

409 Kiani, S. S., et al. (2021). "Investigation of Cu/Zn/Ag/Mo-based impregnated activated carbon for 410 the removal of toxic gases, synthesized in aqueous media." Diamond and Related Materials 111: 411108179.

412 Lee, H. C., et al. (2020). "Performance evaluation of TEDA impregnated activated carbon under 413 long term operation simulated NPP operating condition." Nuclear Engineering and Technology.

414 Lodewyckx, P., et al. (2004). "The Wheeler-Jonas equation: a versatile tool for the prediction of 415 carbon bed breakthrough times." Carbon 42(7): 1351-1355.

416 Lua, A. C. and J. Guo (2001). "Adsorption of sulfur dioxide on activated carbon from oil-palm 417 waste." Journal of Environmental Engineering 127(10): 895-901.

418 Mahle, J. J., et al. (2010). "Role of TEDA as an activated carbon impregnant for the removal of 419 cyanogen chloride from air streams: synergistic effect with $\mathrm{Cu}$ (II)." The Journal of Physical 420 Chemistry C 114(47): 20083-20090.

421 Muzarpar, M. S., et al. (2020). "The Adsorption Mechanism of Activated Carbon and Its 422 Application-A Review." International Journal of Advanced Technology in Mechanical, $423 \quad$ Mechatronics and Materials 1(3): 118-124.

424 Myers, A. (2002). "Thermodynamics of adsorption in porous materials." AIChE journal 48(1): $425 \quad 145-160$. 
426 Perera, M. S. A., et al. (2012). "Estimation of gas adsorption capacity in coal: a review and an 427 analytical study." International Journal of Coal Preparation and Utilization 32(1): 25-55.

428 Sumathi, S., et al. (2010). "Adsorption isotherm models and properties of SO2 and NO removal 429 by palm shell activated carbon supported with cerium (Ce/PSAC)." Chemical Engineering Journal $430 \quad$ 162(1): 194-200.

431 Wen, J., et al. (2021). "Bimetal cobalt-Iron based organic frameworks with coordinated sites as 432 synergistic catalyst for fenton catalysis study and antibacterial efficiency." Colloids and Surfaces 433 A: Physicochemical and Engineering Aspects 610: 125683.

434 Wu, L.-C., et al. (2007). "Removal of hydrogen sulfide and sulfur dioxide by carbons impregnated 435 with triethylenediamine." Journal of the Air \& Waste Management Association 57(12): 14614361468.

437 Yang, M., et al. (2020). "Biosynthesis of nano bimetallic Ag/Pt alloy from Crocus sativus L. 438 extract: biological efficacy and catalytic activity." Journal of Photochemistry and Photobiology B: $439 \quad$ Biology 212: 112025.

440 Yi, H., et al. (2014). "Adsorption of SO2, NO, and CO2 on activated carbons: equilibrium and 441 thermodynamics." Journal of Chemical \& Engineering Data 59(5): 1556-1563.

442 Zhou, C., et al. (2011). "A simple method for calculating the overall adsorption rate constant in 443 the Wheeler-Jonas equation." Adsorption Science \& Technology 29(1): 71-82.

444 Zhou, J., et al. (2014). "Study on adsorption performance of coal based activated carbon to 445 radioactive iodine and stable iodine." Annals of Nuclear Energy 72: 237-241. 
446 Zhou, X., et al. (2018). "Capture of pure toxic gases through porous materials from molecular 447 simulations." Molecular Physics 116(15-16): 2095-2107.

448 Zhou, X., et al. (2012). "Thermodynamics for the adsorption of SO2, NO and CO2 from flue gas 449 on activated carbon fiber." Chemical Engineering Journal 200: 399-404. 